\title{
The Discussion of Air Conditioning Condensed Water Recycle Dai Jun ${ }^{1}$, Chen Yao ${ }^{1}$
}

${ }^{1}$ College of Environment Sciences and Engineering, Chang'an University; Xi'an 710054, China; ${ }^{\mathrm{a} e m a i l}$

Keywords: Condensate Recycle, Psychometric Chart, Enhance Heat Transfier, Humidification, Drop Irrigation

\begin{abstract}
The temperature of the evaporator is lower than the air dew point temperature when the air conditioning is running in summer. The vapor in the air condenses into a large amount of water on the surface of the evaporation pan. Conventional processing methods of condensed water now are directly discharged to the outside while it can not only cause the waste of energy but also has an bad effect on the architectural appearance. Recycling device split-type air conditioners' condensed water can recycle micro-thermal condensate water making full use of energy resources. In the meanwhile it can also solve the problem of air conditioning condensate water discharging.
\end{abstract}

\section{Introduction}

This paper takes household split-type air conditioning condensate water as the research object. According to the outdoor air is set at parameters of one city in China. The indoor dry bulb temperature $t_{w}=34^{\circ} \mathrm{C}$, relative humidity as 72 percent. Machine air dew point temperature $t_{L}=15^{\circ} \mathrm{C}$, relative humidity $\varphi_{\mathrm{L}}=95$ percent. We ignore the effect of the building structure coming in and room layout on a single room's indoor cooling load.

The air through doors and windows is mainly resulted from the fact conditioner has no independent new air system. The new air volume accounts for fresh are ratio is $m=15$ percent. The $\mathrm{W}$ point means the new air state and the return air state is described as point $\mathbb{N}$. The state point $\mathrm{O}$ is determined by mix of new air and return air in proportion. Point $\mathrm{O}$ reaches the air supply state to points $\mathrm{N}$ through the evaporator, senling it back indoor to absorb moisture and then it return to the state point $\mathrm{N}$ as shown in figure1.

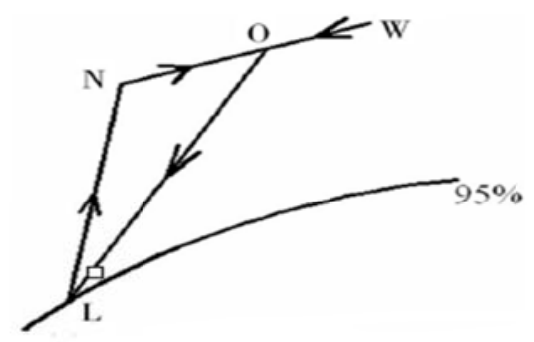

Fig. 1 The new air combined cycle on I-D diagrm

The following parameters can be found in the psychrometric chart:

$\mathrm{d}_{\mathrm{N}}=10.62 \mathrm{~g} / \mathrm{kg}, \quad \mathrm{h}_{\mathrm{N}}=53.33 \mathrm{~kJ} / \mathrm{kg}, \quad \mathrm{d}_{\mathrm{w}}=24.75 \mathrm{~g} / \mathrm{kg}, \quad \mathrm{h}_{\mathrm{w}}=97.81 \mathrm{~kJ} / \mathrm{kg}, \quad \mathrm{d}_{\mathrm{L}}=10.22 \mathrm{~g} / \mathrm{kg}$, $\mathrm{hL}=40.99 \mathrm{~kJ} / \mathrm{kg}$

The state point $\mathrm{O}$ can be calculated as follows:

$\mathrm{d}_{\mathrm{o}}=\left(\mathrm{Qw} \times \mathrm{d}_{\mathrm{w}}+\mathrm{q}_{\mathrm{N}} \times \mathrm{d}_{\mathrm{N}}\right) / \mathrm{q}_{\mathrm{w}}+\mathrm{q}_{\mathrm{N}}(1)$ 
In the above equation,

$\mathrm{q}_{\mathrm{w}}$ - the fresh air, $\mathrm{q}_{\mathrm{w}}=\mathrm{q} \times \mathrm{m}=800 \times 5$ percent $=120 \mathrm{~m}^{3} / \mathrm{h}(2)$

$\mathrm{q}_{\mathrm{N}}$-the return air, $\mathrm{q}_{\mathrm{N}}=\mathrm{q}-\mathrm{qw}=800-120=680 \mathrm{~m}^{3} / \mathrm{h}(3)$

After calculating, we can get:

$\mathrm{d}_{\mathrm{o}}=12.74 \mathrm{~g} / \mathrm{kg}$.

The number of condensed water forming:

$\Phi=\rho \mathrm{V}\left(\mathrm{d}_{\mathrm{o}}-\mathrm{d}_{\mathrm{L}}\right)(4)$

In the above equation,

$\rho$-Air density involved in cycling. $\rho=1.3 \mathrm{~kg} / \mathrm{m}^{3}$,

$\mathrm{V}$-circulating air quantity. $\mathrm{V}=\mathrm{q}=800 \mathrm{~m}^{3} / \mathrm{h}$.

After calculating we can get the condensate quantity $\Phi=2.62 \mathrm{~kg} / \mathrm{h}$

From the above calculation, what can be seen is that the condensate water produced by air conditioning is related to actual performance parameters of the air conditioner itself, indoor parameters, air ratio and other factors. Great change has seldom taken place in the indoor parameters and the new air given a fixed modelof some special machine type. Then we study the change of indoor paramter (temperature and relative humidity) and the amount of condensation, as shown in chart 1.

Chart1. condensate water quantity in different outdoor parameters (unit: $\mathrm{kg} / \mathrm{h}$ )

\begin{tabular}{cccccc}
\hline \hline \multirow{2}{*}{ temperature } & \multicolumn{5}{c}{ Relative humidity } \\
& 68percent & 70percent & 72percent & 74percent & 80percent \\
\hline 30 & 1.64 & 1.73 & 1.81 & 1.9 & 2.16 \\
34 & 2.40 & 2.51 & 2.62 & 2.73 & 3.07 \\
40 & 3.88 & 4.04 & 4.20 & 4.36 & 4.84 \\
\hline
\end{tabular}

From the chart we can know that condensatate water increases with the increase inrelative humidity and temperature. Temperature can produce larger effect on the condensate water.

\section{Method}

The condensed water collection rank is installed in the lower part of air conditioning outside unit. We can collect the condensate water by the water basin in the lower part of indoor evaporator, and then send it to the indoor condensate recovery component and outdoor condensate recovery component separately.

The outdoor component is made of micro-pumps and sprayer, and it's used to enhance heat transfer by spraying the condensate water at the condenser finned surface of outdoor component to improve the effect of air conditioning refrigeration so as to achieve the aim of saving electricity.

Indoor equipment mainly includes humidifying with cavitycontaining water. The whole humidification machine is supported by the wooden holder. The ultrasonic humidifier is equipped at the bottom of the containing water cavity. The humidification machine can be controlled by floating contact liquid level switch. Condensate water is recycled as water recourse through the ultrasonic humidifier so that the indoor air humidity is increased to adjust the indoor environment. In the mean while, the branch pipe at the backward of e bulb type ultrasonic humidifying containers is linked to a dropper cultivation device. The indoor component can create a warm and comfortable home environment to improve home comfort. 


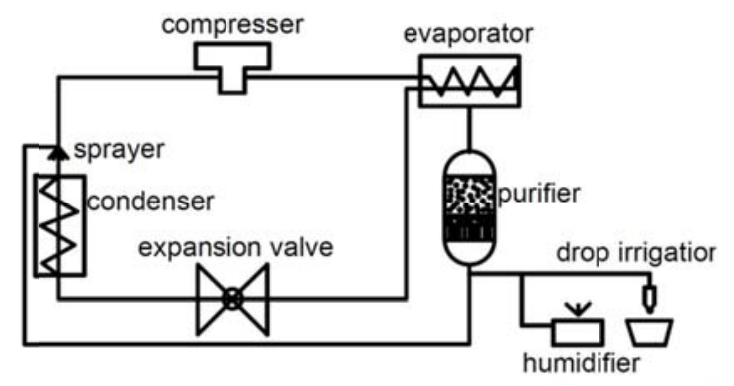

Fig.2 system theory diagram

\section{Complex Composition of Condensed Water from Air-Conditioning}

After analyzing the construction the air conditioning condensate formation analysis, the condensate water is made of the water vapor in the air(it is pure water in the theory). In addition to the dry air and water vapor in the air, it also have dust, bacteria and viruses. When water vapor is condensation in the air, the harmful substance will be taken by the condensed water. In the air pollution, the greater degree of the air pollution, the more the content of harmful substances in the condensate water. So when we using the condensed water, we must purify it before.

Now, we intend to purify condensate in the front of the device, and main measures are as follows:

Quartz sand filter structure: there is activated carbon upper the filter structure, and quartz sand on the second shelf, and pebbles is on lower. It plays supporting role in the filter structure. Micro-flocculation remove suspended solids, particulate matter, colloid, algae, microorganisms and some colloidal substance in the water, and this quartz sand filter to reduce the turbidity in the water. The Quartz sand filter can remove colloidal substance and big particles. When the colloid particles through the multiple media filter of the filter material layer, filter gap of suspended solids from the sieve effect the suspension was trapped in the filter surface is easy. When the filter surface trapping a certain amount of dirt formed membrane, over time the differential pressure across the filter will soon rise, until failure. It needs to use the reverse water backwashing filter material, so that the adhesion in the quartz sand and activated carbon on the surface of the intercept stripping was taken away by the water, resume filtering capabilities.

The use of upper activated carbon, the lower quartz sand: adsorption of residual chlorine(reverse osmosis of residual chlorine adaptability is poor), and adsorption of organic matter and microorganisms removal of chloride ions, organic matter. The shade of the activated carbon filter to reduce the water and purify water taste, and it may be further improve the function of taste; In the Water treatment system, the activated carbon adsorption pre-filter can not be removed by filtration in order to prevent the chlorine-stage reverse osmosis membrane subject to oxidative degradation. In the same time it also leaked over the previous stage adsorption of small organic molecules and other polluting substances, water odor, colloids and pigment, heavy metal ions adsorbed and removed more visible, but it has the effect of reducing the COD. 


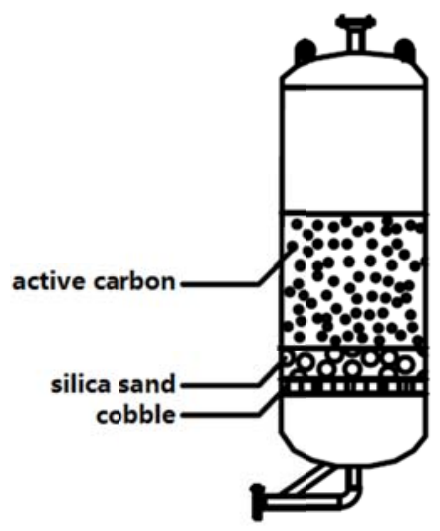

Figure 2.condensed water purification device

The activated carbon filters work is done through the carbon bed. It is consisted by activated carbon particles. And it has a very large number of pores and large specific surface area and a strong physical adsorption capacity. Organic pollutants in water are absorbed through the charcoal bed. In addition, there are a number of oxygen-containing functional groups on the activated carbon tube non-crystalline portion of the surface, so that is effectively activated carbon adsorption of organic pollutants in water of the carbon bed. Activated carbon filters is a more commonly used water treatment equipment. water desalination system as foreyards treatment can effectively ensure stage equipment life, improve water quality and prevent pollution, in particular to prevent post-stage reverse osmosis membranes, ion exchange resins, etc. More than oxygen poisoning pollution freestate.

\section{The Rationality of the Device}

In order to verify that the rationality of air conditioning evaporator condensate can be treated as a medium to strengthen Heat transfer $\mathrm{O}$, condenser heat exchanged calculation is necessary.

We can know the refrigerating capacity by checking the enthalpy wet figure:

$$
\begin{aligned}
Q & =\rho q\left(h_{N}-h_{L}\right) \\
& =1.3 \times 800 \times(63.33-40.99) \\
& =3565 \mathrm{~W}
\end{aligned}
$$

When we don't use the condensate water, energy efficiency can be calculated as:

$C O P=2.65$

The input power can be calculated as:

$W=Q / C O P=3565 / 2.65=1345 W$

The condenser heat dissipating capacity can be calculated as:

$Q_{k}=W+Q=1345+3565=4910 W \quad(7)$

When the condensate water is collected, evenly sprayed onto the condeniser fin. The heat took away because of the vaporization can be calculated as: 


$$
Q_{\text {vap }}=2.62 \times 2406 / 3600=1751 \mathrm{~W}
$$

When the condensation temperature is $40^{\circ} \mathrm{C}$, the latent heat of water vaporization at this time is $2406 \mathrm{~J} / \mathrm{g}$. After using the condensed water, condenser heat release is:

$Q_{k}=4910+1751=6661 \mathrm{~W}$

The amount of heat dissipation rate increase is:

$1751 / 4910=35.66 \%$

Thus, condenser heat dissipating capacity has improved significantly.

\section{Result}

When the air conditioner rated refrigerating capacity is $5000 \mathrm{w}$ and ts theoretical condensed water is $2.62 \mathrm{~kg} / \mathrm{h}$, the amount of condensate produced by air conditioning is related to circulating air flow, indoor parameters, and air conditioner cooling volume.

There is a large amount of condensate water. After being purificated, the condensate water can be put different devices( humidifiers, watering for potted plants) to play an important role.It is very practical and the use of condensate water-saving effect can be achieved in the room. It uses the condensate water from the air conditioning indoor evaporator after purification, then it spray on the condenser fins. Itfunctions to transfer heat enhance and save power.

\section{Conclusion}

Based on the theoretical calculation,the air-conditioning condensation water recycling energy efficiency, the analysis of leads to the following conclusions:

In fact, the amount of condensate water produced by air conditioning is related to circulating air flow, indoor parameters, and air conditioner cooling volume.

Through analysis, the reasonable use of air conditioning condensate water can not only produce considerable economic benefits, but also eliminate the adverse effects of condensate water on the environment.

Its complex features include enhanced heat transfer condenser fin, indoor humidification, drip pot in this device. The condensate water recycled can effectively reduce the ambient temperature around the condenser, adjust the indoor humidity, water plants automatically, and thus save water and energy.

\section{References}

[1] Ji Liming. and Qi Yingxia 2006. Exploration on the utilization and energy saving

Of condensing water From household airconditioner. Refrigeration. 41(6), 710-718.

[2] Giovanni Cortella, Marco Manzan, Gianni Comini. CFD simulation of refrigerated display cabinets $[\mathrm{J}]$.International Journal of Refrigeration, 2001，24( 3) :250-260

[3] JiJ. and PeiG.Performance simulation and experimental analysis hot water heaters one machine alone mode - air conditioning. HVAC, 42(7), 2523-2529.

[4] Hui-min jiang, wang Yang, Ma Zuiliang. With a hot water supply of household air conditioner 
discussion [J]. Journal of architectural ventilation and air conditioning heat. 2004, 23 (1) : 48-51

[5] KAREN GUZ. Condensate Water Recovery[J]. ASHRAAEjournal,2005(6):54-56.

[6] Kevin Teller. AC System Utilizing Condensate Water to Precool HotGas[P]. United State Patent: US006463751B1,Oct.15,2002.

[7] Giovanni Cortella, Marco Manzan, Gianni Comini. CFDsimulation of refrigerated display cabinets $[\mathrm{J}]$. InternationalJournal of Refrigeration,2001,24( 3) : 250-260.

[8] Guo-liang Ding, Oellrich r. L refrigerator inside air temperature field and flow fieldOptimization study [J]. Journal of refrigeration, 1998 (1) : 22-27.

[9] Xiao-hua $\mathrm{Wu} \mathrm{Wu} \mathrm{Ye} \mathrm{is,} \mathrm{xiao-lin} \mathrm{cao.} \mathrm{Indoor} \mathrm{temperature} \mathrm{field} \mathrm{and} \mathrm{flow} \mathrm{field} \mathrm{of} \mathrm{the}$ fridgeSimulation and structural optimization [J]. Journal of refrigeration, 2004, (1):36-38.

[10] Fu-jun Wang. Computational fluid dynamics analysis, theory and CFD software Application [M]. Beijing: tsinghua university press, 2004.

[11] Qing-yong Su, He Guangxing, li. A cruise ship cabin temperature air conditioning cooling processField and velocity field of the dynamic simulation [J]. Cryogenic and superconducting, 2008, 4(2) : 51-54. 